\title{
An evaluation of perfusion techniques in the study of water and electrolyte absorption in man : the problem of endogenous secretions
}

\author{
G. E. SLADEN AND A. M. DAWSON ${ }^{1}$ \\ From St Bartholomew's Hospital, London
}

Small intestinal perfusion techniques have become widely used in recent years in the study of quantitative aspects of intestinal absorption in man. The simple double-lumen tube technique has usually been used, especially in studies on the absorption of monosaccharides (Schedl and Clifton, 1963a; Holdsworth and Dawson, 1964), disaccharides (Gray and Ingelfinger, 1965; McMichael, Webb, and Dawson, 1967), and aminoacids (Fleshler, Butt, and Wismar, 1966). A major theoretical disadvantage of this method is that it makes no allowance for endogenous gastrointestinal secretions, which may contaminate the perfusion zone from above. It can be shown that such contamination may result in serious underestimation of absorption rates, especially of water, sodium, and other electrolytes. The use of a proximally situated occlusive balloon (Phillips and Summerskill, 1966) and the incorporation of a mixing segment by using a triple-lumen tube (Cooper, Levitan, Fordtran, and Ingelfinger, 1966) have both been advocated in order to obviate this difficulty, and it has been concluded that the two-lumen tube technique, used in the study of water and electrolyte absorption, will result in gross and unacceptable inaccuracies (Fordtran, 1966). However, there is doubt about the magnitude of endogenous contamination and hence of its practical significance. This has been assessed indirectly, in the present studies, by comparing rates of water and sodium absorption from saline and glucose-saline mixtures, using both the doubleand triple-lumen techniques. If significant contamination occurs, the results obtained by the two methods should differ by an amount equal to the mean rate of contamination. Some of the difficulties inherent in the use of the triple-lumen tube technique are also described.

\section{METHODS}

The two perfusion systems are shown diagrammatically 'Correspondence to Dr A. M. Dawson, St Bartholomew's Hospital, London, EC1. in Figures 1 and 2. The two-lumen technique is essentially similar to that described by Holdsworthand Dawson (1964) and the three-lumen technique has been described and assessed by Cooper et al (1966) and by Whalen, Harris, Geenen, and Soergel (1966).

Polyvinyl double-lumen tubing (Portex MLT/B, external diameter $4.2 \mathrm{~mm}$ ) was used, with a mercury bag attached. Radioopaque single-lumen tubing (Portex SH 85 R3, external diameter $2.5 \mathrm{~mm}$ ) was attached, using vinyl cement (Portex) in the construction of the triplelumen tubes. An orifice was cut into each lumen, to give test segment lengths of $30 \mathrm{~cm}$ and, in the case of the triple-lumen tube, a mixing segment length of $15 \mathrm{~cm}$. All materials were obtained from Portland Plastics Ltd, Hythe, Kent.

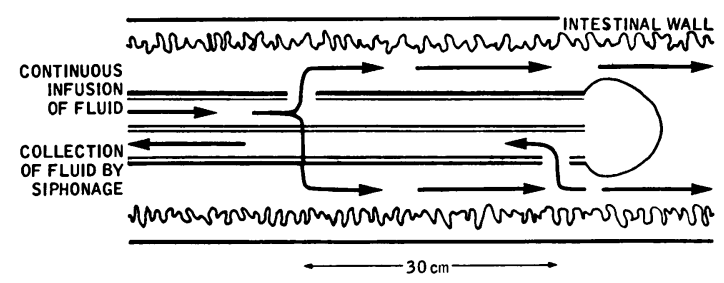

FIG. 1. Double-lumen perfusion system.

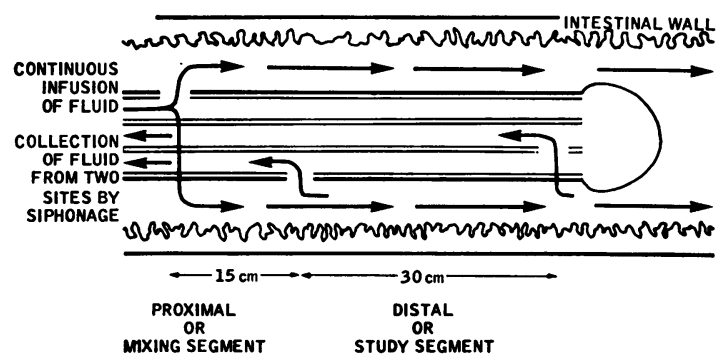

FIG. 2. Triple-lumen perfusion system. 
Sixteen subjects have been studied with the doublelumen method and 13 subjects with the triple-lumen method. All were volunteers without evidence of small bowel disease. The tubes were swallowed on the night before the test and the position of the tubes was checked radiologically on the following morning. In every case, the tube was positioned so that the infusion orifice was just distal to the duodeno-jejunal flexure. In the case of the three-lumen tube, delay in transit was a major problem initially and subsequently very fine polythene tubing (external diameter $1 \mathrm{~mm}$ ) was introduced through one of the lumens and connected to a distally situated inflatable balloon. This was used to stimulate peristalsis and was successful in most cases. The subjects were fasting for 12 hours before the test.

The solutions were pumped at constant rates through the infusion orifice, using a Watson-Marlow pump (H.F. inducer, Watson Marlow Ltd, Marlow, Bucks) from bottles placed in a water bath at $37^{\circ} \mathrm{C}$. An equilibration period of 30 minutes was allowed in order to set up a steady state, but at the slowest infusion rate $(11 \mathrm{ml} / \mathrm{min})$ this was increased to 60 minutes. During the steady state, samples were obtained from the collection orifices by siphonage, but occasional small aspirations were required. Three timed 10 -minute samples were obtained from each orifice and, in the case of the threelumen tube, the proximal siphonage system was controlled by a gate-clip to give flows of 1 to $2 \mathrm{ml} / \mathrm{min}$. Distal siphonage rates were uncontrolled. Each subject was perfused with six to seven different solutions during a single day.

The solutions perfused were isotonic saline and a series of isotonic glucose-saline mixtures. Glucose concentrations ranged from $5.6 \mathrm{mM}$ to $280 \mathrm{mM}$, and appropriate amounts of saline were added to make the solutions isotonic. The osmolality of the solutions was checked before perfusion, using an Advanced Osmometer (Advanced Instruments, Inc., Newton Highlands, Massachusetts, USA). The solutions all contained the non-absorbed marker substance polyethylene glycol (PEG) in a concentration of $2.5 \mathrm{~g} / 1$., to indicate water absorption or secretion (Schedl, 1966).

The samples obtained were analysed for PEG using the turbidometric method of Hydén (1956). Glucose was estimated as total reducing substance using dinitrosalicylic acid (Sumner, 1924) on protein-free filtrates obtained during the PEG determinations. Sodium was estimated by flame photometry (EEL photometer, Evans Electroselenium Ltd, Halstead, Essex).

\section{CALCULATIONS}

Absorption or secretion rates were calculated from the data as mean figures of triplicate observations and expressed as mmoles, m-equiv, or $\mathrm{ml}$ per hour for a $30 \mathrm{~cm}$ segment of jejunum. The calculations were as follows:

\section{Two-lumen tube}

$$
\begin{aligned}
& \text { water absorption }=\mathrm{F} \times\left(1-\frac{\mathrm{PEG}_{\mathrm{I}}}{\mathrm{PEG}_{\mathrm{A}}}\right) \\
& \text { solute absorption }=\mathrm{F} \times\left(\mathrm{S}_{\mathrm{I}}-\mathrm{S}_{\mathrm{A}} \frac{\mathrm{PEG}_{\mathrm{I}}}{\mathrm{PEG}_{\mathrm{A}}}\right)
\end{aligned}
$$

$$
\begin{aligned}
& \text { where } F \quad=\text { initial infusion rate } \\
& \text { PEG } \left._{I}\right\}=\text { initial PEG and solute } \\
& \left.\mathrm{S}_{\mathrm{I}}\right\}=\text { concentrations } \\
& \left.\begin{array}{l}
\text { PEG }_{\mathbf{A}} \\
\mathbf{S}_{\mathbf{A}}
\end{array}\right\}=\begin{array}{l}
\text { PEG and solute concentration in } \\
\text { samples }
\end{array}
\end{aligned}
$$

Three-lumen tube

Absorption from the distal $30 \mathrm{~cm}$ segment

water absorption $=$

$$
F\left(\frac{P^{P E G_{I}}}{\overline{P E G}_{P}}-\frac{P E G_{I}}{\overline{P E G}_{D}}\right)-A\left(1-\frac{\text { PEG }_{P}}{\overline{P E G}_{D}}\right)
$$

solute absorption $=$

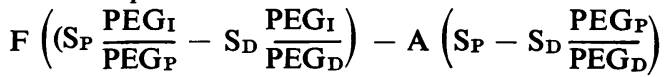

$$
\begin{aligned}
& \text { where } \left.P_{P G}\right\}=\text { PEG and solute concentrations in } \\
& \left.\begin{array}{l}
\mathrm{S}_{\mathbf{P}} \\
\mathbf{P E G}_{\mathbf{D}} \\
\mathrm{S}_{\mathbf{D}} \\
\mathbf{A}
\end{array}\right\}=\begin{array}{l}
=\begin{array}{l}
\mathbf{P} \\
\text { the proximal samples } \\
\text { PEG and solute concentrations in } \\
\text { the distal samples }
\end{array} \\
=\text { proximal siphonage rate }
\end{array}
\end{aligned}
$$

RESULTS

ABSORPTION OF WATER AND SODIUM FROM ISOTONIC SALINE The mean results of two series of saline perfusions are shown in Table I. Absorption from isotonic saline shows considerable variation between individual subjects and in many cases there is net secretion of water and sodium into the lumen. It is very unusual to find marked absorption, and the mean rates of the series are very small compared with the amounts available for absorption. The mean absorption rates for water are not significantly different from zero. There is no significant difference between the results obtained by the two methods and this strongly suggests that the low results are not explicable on the basis of underestimation of absorption, consequent upon contamination by endogenous gastrointestinal secretion from above. If this had been the case, appreciable absorption would have been expected using the triple-lumen tube, and the results obtained using the two techniques would have been significantly different.

ABSORPTION OF WATER AND SODIUM FROM ISOTONIC GLUCOSE-SALINE MIXTURES Mean results of several series of observations using the two methods are shown in Figures 3 and 4. It has been found in concurrent studies, using the double-lumen tube and a wide range of glucose concentrations, that maximum rates of sodium and water absorption are obtained from $56 \mathrm{mM}$ and $84 \mathrm{mM}$ glucose solutions. The same rate of water absorption occurs from $140 \mathrm{mM}$ glucose, but sodium absorption from this mixture is negligible. (These results will be presented in detail elsewhere.) In order to compare the two perfusion methods, it is essential to have comparable glucose concentrations and flow rates 
of fluid entering the test segment of the doublelumen tube and the distal segment of the triplelumen tube. Allowance has to be made for absorption of glucose and water by the proximal $15 \mathrm{~cm}$ segment in the case of the triple-lumen tube, and the effects of this will be described in the next section. By using a high initial glucose concentration $(138 \mathrm{mM})$ and a range of flow rates, it has been possible to obtain approximately comparable conditions.

There is little difference between the water absorption rates obtained by the two methods, although if the two maximum rates are compared by the $t$ test, the difference just achieves statistical significance $(t=2.32 \mathrm{P}<0.05)$. There has been no underestimation of maximum absorption rates by the use of the double-lumen tube. Observed differences are in the opposite direction.

The sodium absorption rates are significantly less with the triple-lumen tube at all flow rates (t test: $P<0.01$ ). This is probably related to the fact that the luminal sodium concentrations of fluid entering the test segment are lower than in the double-lumen tube series. This resulted from the necessity to use a higher initial glucose concentration than may have been desirable, in order to obviate the effects of proximal glucose absorption. It has certainly not been possible to demonstrate underestimation of sodium absorption by the doublelumen method, although it is admittedly difficult to obtain exactly comparable luminal conditions in the two series.

EFFECTS OF ABSORPTION BY THE PROXIMAL SEGMENT OF THE TRIPLE-LUMEN TUBE The concentration of solute and flow rate of solution entering the test segment is difficult to control, because absorption of glucose and fluid occurs proximally in the mixing segment. The effects of such absorption are shown in Tables II and III and it can be seen that the glucose concentration falls steeply along the proximal $15 \mathrm{~cm}$, especially at the slowest initial flow rate. Changes in the flow rate itself are also considerable when glucose-saline mixtures are perfused and there is a considerable variation of individual results, as shown by the standard

TABLE I

ABSORPTION OF WATER AND SODIUM FROM ISOTONIC SALINE USING A 30 CM PERFUSION SEGMENT AND AN INFUSION RATE OF $20 \mathrm{ML} / \mathrm{MIN}^{1}$

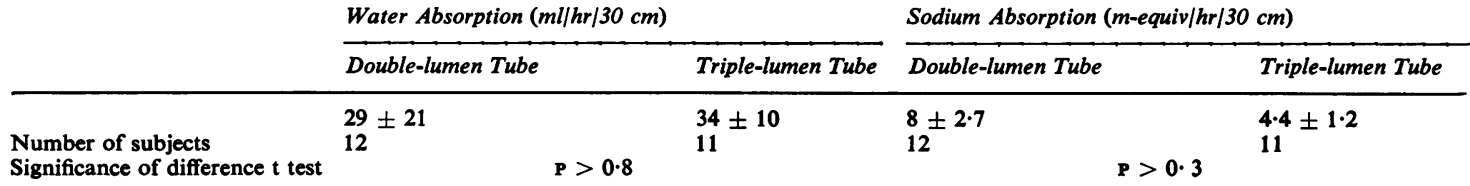

1 Mean rates \pm 1 SEM.

TABLE II

GLUCOSE CONCENTRATION CHANGES DOWN A 45 CM SEGMENT DURING PERFUSIONS OF ISOTONIC $138 \mathrm{mM}$ GLUCOSE-SALINE MIXTURES AT THREE INITIAL PERFUSION RATES ${ }^{1}$

\begin{tabular}{|c|c|c|c|c|}
\hline \multirow[t]{2}{*}{ Initial Perfusion Rate (ml/min) } & \multirow[t]{2}{*}{ Initial Concentration $(m M)$} & \multicolumn{2}{|c|}{ Sample Concentration $m M$} & \multirow[t]{2}{*}{ Number of Subjects } \\
\hline & & Proximal $(15 \mathrm{~cm})$ & Distal $(45 \mathrm{~cm})$ & \\
\hline $\begin{array}{l}11 \\
20 \\
28\end{array}$ & $\begin{array}{l}137 \pm 4 \\
138 \pm 3 \cdot 6 \\
137 \pm 3\end{array}$ & $\begin{array}{r}70 \pm 13 \\
103 \pm 16 \\
117 \pm 10\end{array}$ & $\begin{array}{l}36 \pm 25 \\
75 \pm 22 \\
96 \pm 12 \cdot 5\end{array}$ & $\begin{array}{r}8 \\
10 \\
10\end{array}$ \\
\hline
\end{tabular}

TABLE III

CHANGE IN FLOW RATE RESULTING FROM WATER ABSORPTION DURING PERFUSIONS OF ISOTONIC SALINE AND ISOTONIC $138 \mathrm{mM}$ GLUCOSE-SALINE MIXTURES AT THREE INITIAL FLOW RATES ${ }^{2}$

\begin{tabular}{|c|c|c|c|c|}
\hline & $\begin{array}{l}\text { Initial Perfusion Rate } \\
(\mathrm{ml} / \mathrm{min})\end{array}$ & $\begin{array}{l}\text { Flow Past Proximal Orifice } \\
(\mathrm{ml} / \mathrm{min})\end{array}$ & $\begin{array}{l}\text { Flow Past Distal Orifice } \\
(\mathrm{ml} / \mathrm{min})\end{array}$ & Number of Subjects \\
\hline $\begin{array}{l}\text { Glucose-saline } \\
\text { Saline }\end{array}$ & $\begin{array}{l}\left\{\begin{array}{l}11.4 \pm 1 \\
20.6 \pm 2 \\
28 \pm 1\end{array}\right. \\
20.8 \pm 1.6\end{array}$ & $\begin{array}{l}6.7 \pm 1.5 \\
15.5 \pm 3.2 \\
23.7 \pm 2.7 \\
20.1 \pm 3\end{array}$ & $\begin{array}{l}4 \cdot 4 \pm 1 \cdot 4 \\
11 \pm 5 \cdot 3 \\
20 \cdot 4 \pm 4 \\
20 \cdot 2 \pm 4\end{array}$ & $\begin{array}{r}8 \\
11 \\
10 \\
13\end{array}$ \\
\hline
\end{tabular}

1 Means \pm 1 SD. 


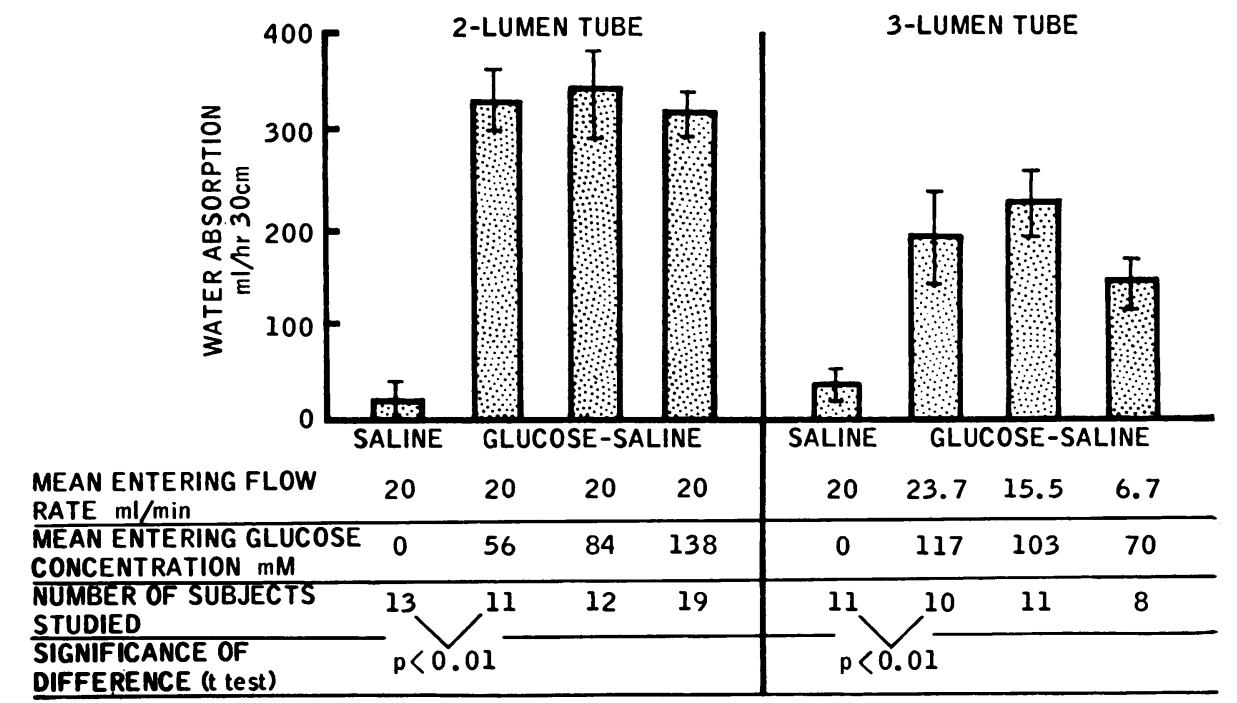

FIG. 3. Water absorption from isotonic saline and glucose-saline mixtures, using $30 \mathrm{~cm}$ lengths of jejunum and comparing the double-lumen and triple-lumen perfusion methods. Mean values in $\mathrm{ml} / \mathrm{hr}$ per segment $\pm 1 S E M$.

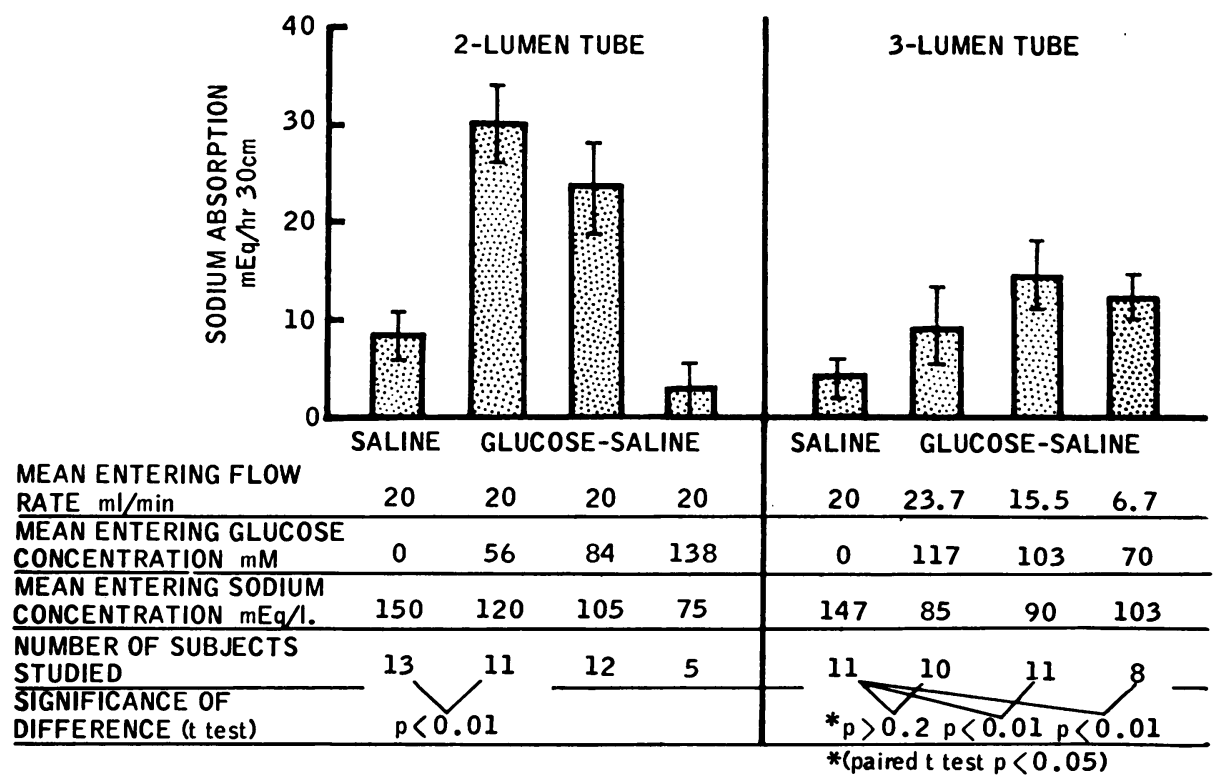

FIG. 4. Sodium absorption from isotonic saline and glucose-saline mixtures, using $30 \mathrm{~cm}$ lengths of jejunum and comparing the double-lumen and triple-lumen perfusion methods. Mean values in m-equiv/hr per segment \pm 1 SEM. 
deviations. This difficulty in controlling conditions at the point of entry to the test segment is a major practical disadvantage of the triple-lumen technique.

\section{DISCUSSION}

Using perfusion techniques, Schedl and Clifton (1963b) and Malawer, Ewton, Fordtran, and Ingelfinger (1965) have shown that glucose stimulates water and sodium absorption from the normal human jejunum. The present results are in agreement with these findings, but show, in addition, that the absorption rates are very similar, whether one uses a double- or triple-lumen technique. This raises doubts about the necessity of using a triple-lumen tube in studies of this type.

The main object of the triple-lumen tube is to make allowance for endogenous gut secretions contaminating the perfusion zone from above. There is doubt about the magnitude of this contamination rate in the normal fasting upper jejunum. Calculations based on estimated upper gastrointestinal secretion rates led Schedl and Clifton (1963b) to conclude that the contamination rate was unlikely to be greater than $0.5-1.0 \mathrm{ml} / \mathrm{min}$ and this was considered to be small enough, relative to the perfusion rate, to ignore. However, there is a lack of reliable information about normal secretion rates of bile, pancreatic juice, etc, in the fasting state, and calculations of this type fail to take into consideration absorption of fluid proximal to the perfusion zone.

Whalen, Harris, Geenen, and Soergel (1966) attempted to measure the rate of flow of fasting intestinal contents directly, by using a very slow perfusion system and 'marking' the fasting contents with PEG. They obtained a mean value of $2 \cdot 16 \pm$ $1.32 \mathrm{ml} / \mathrm{min}$. Such a technique is open to the criticism that the transit time of fluid in the perfusion system $(0.44 \mathrm{ml} / \mathrm{min}$ and a $45 \mathrm{~cm}$ segment length) would be very slow indeed and it is possible that PEG may remain adherent to the mucosal surface in such circumstances, for Jacobson, Bondy, Broitman, and Fordtran (1963) have shown that correlation between measured and calculated volumes using PEG is much better in a fairly fast perfusion system than in a closed loop. A fast perfusion system may wash PEG down the segment, and at the very slow flow rates described above, the situation would approximate to that of a closed loop. This could, theoretically, result in overestimation of flow rates of fasting intestinal contents. Whalen et al (1966) also assess contamination indirectly by extrapolating PEG values expressed in relation to distance along the perfusion segment. They give evidence that absorption rates of water are uniform with distance beyond the first $15 \mathrm{~cm}$ and so extrapolation back to the infusion point will estimate the actual flow of fluid at this point, and this will be equal to the sum of the infusion rate and the contamination rate. Their results were comparable to those obtained by the direct method. But, their solutions contained $16.7 \mathrm{mM}$ glucose and most of this was absorbed from the proximal $15 \mathrm{~cm}$ of the system. Since the osmolality of the gut contents changed little, it seems very likely that the absorption rate of water would be greater from this $15 \mathrm{~cm}$ segment than from subsequent ones and, if this is so, it is invalid to extrapolate backwards in an attempt to assess contamination indirectly.

However, if this estimate of the contamination rate is accepted, it would suggest that the use of the double-lumen tube would seriously underestimate absorption rates of water and sodium. It can easily be shown that water absorption would be underestimated by an amount equal to the contamination rate and, if the latter is about $2 \mathrm{ml} / \mathrm{min}$, this will be highly significant. For example, maximum water absorption rates of 5 to $6 \mathrm{ml} / \mathrm{min}(300-360 \mathrm{ml} / \mathrm{hr})$, obtained using a $30 \mathrm{~cm}$ segment and a double-lumen technique, would be underestimated by $50 \%$. The effects on solute absorption will depend on the concentration of solute in the contaminating fluid and, in the case of sodium, this will be approximately $140 \mathrm{~m}$-equiv/l. This would underestimate sodium absorption by as much as $15 \mathrm{~m}$-equiv/hr, assuming a contamination rate of $2 \mathrm{ml} / \mathrm{min}$, and this is over $75 \%$ of the maximum sodium absorption rate obtained using the double-lumen tube. The effects are likely to be negligible in the case of substances such as glucose, which are present in low concentration in fasting intestinal contents and which are ordinarily absorbed avidly.

Reasoning on these lines suggests that a comparison of absorption rates of sodium and water, measured with the two- and three-lumen techniques, should give an indirect estimate of the contamination rate and of its practical significance. In fact, the results are surprisingly similar and, if anything, water and sodium absorption rates are less when the triple-lumen technique is used. This may be partly explained by the fact that the luminal solute concentrations (especially sodium) and flow rates in the test segments are not exactly the same in the two groups of observations. However, by using an adequate initial glucose concentration and a range of perfusion rates, it has not been possible to demonstrate that the double-lumen tube results in any significant underestimation of water and sodium absorption rates. This can only mean that, in the normal fasting jejunum, contamination rates 
are in fact negligible and that it is valid to use the two-lumen tube in studies of this type. Contamination undoubtedly occurs, as is shown by the frequent bile staining of intestinal samples, and it seems reasonable to conclude that the bulk of sodium and water contained in such contaminating fluid may be absorbed proximally in the duodenum and so not enter the perfusion zone.

The only comparable studies in man are those of Malawer et al (1965), already referred to. Their maximum water and sodium absorption rates are strikingly similar to those described above for the double-lumen method. Their results have only been presented in abstract form, but they claim to have taken endogenous secretions into account, presumably by the use of a triple-lumen tube.

The validity of the double-lumen method probably only applies to a series of observations in normal subjects. In individual subjects, using the triplelumen tube, there is occasionally considerable net gain of fluid by the proximal segment, which may represent contamination, especially if the tube is situated too far proximally.

The use of the triple-lumen tube introduces difficulties, which result from the absorption of glucose and water by the proximal mixing segment. This will greatly affect the solute concentration and flow rate of fluid at the point of entry to the distal segment, especially at low initial flow rates. These conditions cannot, therefore, be controlled accurately and this makes it very difficult to study kinetic aspects of absorption. Absorption rates from the distal segment should be related to these conditions, rather than to concentrations or flow rate of the infusion fluid. Whalen et al (1966), using the triple-lumen tube, found that the infusion of $16.7 \mathrm{mM}$ glucose had no apparent effect on sodium or water absorption from the distal segment and concluded that this absorption was independent of the presence of glucose. Their data show quite clearly that most of the glucose was absorbed by the proximal segment and did not in fact enter the test segment.

The use of occlusive balloons (Phillips and Summerskill, 1966) is open to the theoretical criticism that they may stimulate peristalsis and cause buckling of the gut in the tube. Their published results have shown the efficacy of the occlusion, but they have not studied aspects of water or electrolyte absorption that can be compared directly with the present findings.

The double-lumen tube method can, therefore, give valid results in studies of water and electrolyte absorption of the type described, and its simplicity has positive advantages from several points of view.

\section{SUMMARY}

Double- and triple-lumen tube perfusion techniques have been used in 16 and 13 normal subjects, respectively, in a study of water and sodium absorption in man. The results have been compared in an attempt to assess, indirectly, the magnitude of contamination of the perfusion zone by endogenous gastrointestinal secretions from above. The two methods give similar quantitative rates of water and sodium absorption and this suggests that contamination is negligible in the normal fasting upper jejunum.

Absorption of solute and water by the proximal segment of the triple-lumen tube produces difficulties in the control of the experimental situation and in the interpretation of results.

It is, therefore, considered valid, simpler and preferable to use the double-lumen tube for studies of this type in normal subjects.

This work has been supported by grants from the Medical Research Council. We would also like to thank the Board of Governors of St Bartholomew's Hospital for financial support.

\section{REFERENCES}

Cooper, H., Levitan, R., Fordtran, J. S., and Ingelfinger, F. J. (1966), A method for studying absorption of water and solute from the human small intestine. Gastroenterology, 50, 1-7.

Fleshler, B., Butt, J. H., and Wismar, J. D. (1966). Absorption of glycine and I-alanine by the human jejunum. J. clin. Invest., 45, 1433-1441.

Fordtran, J. S. (1966). Marker perfusion techniques for measuring intestinal absorption in man. Gastroenterology, 51, 1089-1093.

Gray, G. M., and Ingelfinger, F. J. (1965). Intestinal absorption of sucrose in man: the site of hydrolysis and absorption. J. clin. Invest., 44, 390-398.

Holdsworth, C. D., and Dawson, A. M. (1964). The absorption of monosaccharides in man. Clin. Sci., 27, 371-379.

Hydén, S. (1956). A turbidometric method for the determination of higher polyethylene glycols in biological materials. $K$. Landbr-Högsk. Annlr., 22, 139-145.

Jacobson, E. D., Bondy, D. C., Broitman, S. A., and Fordtran, J. S. (1963). Validity of polyethylene glycol in estimating intestinal water volume. Gastroenterology, 44, 761-767.

Malawer, S. J., Ewton, M., Fordtran, J. S., and Ingelfinger, F. J. (1965). The interrelation between jejunal absorption of sodium, glucose, and water in man. (Abstr.). J. clin. Invest., 44, 1072.

McMichael, H. B., Webb, J., and Dawson, A. M. (1967). The absorption of maltose and lactose in man. Clin. Sci., 33, 135-145.

Phillips, S. F., and Summerskill, W. H. J. (1966). Occlusion of the jejunum for intestinal perfusion in man. Mayo Clin. Proc., 41, 224-231.

Schedl, H. P. (1966). Use of polyethylene glycol and phenol red as unabsorbed indicators for intestinal absorption studies in man. Gut, 7, 159-163.

, and Clifton, J. A. (1963a). Kinetics of intestinal absorption in man: normals and patients with sprue. Proc. 2nd Wld Congr., Gastroent., Munich 1962, 2, 728-732.

,,$--(1963 b)$. Solute and water absorption by the human small intestine. Nature (Lond.), 199, 1264-1267.

Sumner, J. B. (1924). The estimation of sugar in diabetic urine using dinitrosalicylic acid. J. biol. Chem., 62, 287-290.

Whalen, G. E., Harris, J. A., Geenen, J. E., and Soergel, K. H. (1966). Sodium and water absorption from the human small intestine: the accuracy of the perfusion method. Gastroenterology, 51, 975-984. 